\title{
Combined cervicosternotomy and cervicotomy for true retrosternal goiters:a surgical cohort study
}

\author{
S. Van Slycke ${ }^{1,2,3} \cdot$ A.-S. Simons ${ }^{1,4} \cdot$ K. Van Den Heede ${ }^{1} \cdot$ P. Van Crombrugge ${ }^{5} \cdot$ K. Tournoy $^{6,7} \cdot$ P. Simons ${ }^{8}$. \\ H. Vermeersch ${ }^{2,9} \cdot$ N. Brusselaers ${ }^{2,10,11}$
}

Received: 21 January 2021 / Accepted: 11 March 2021 / Published online: 29 March 2021

(c) The Author(s) 2021

\begin{abstract}
Objective Intrathoracic goiters are a heterogeneous group characterized by limited or extensive substernal extension. Whereas the former can be treated through cervicotomy, the latter sometimes requires a cervicosternotomy. Whether cervicosternotomy leads to more morbidity remains unclear.

This study aimed to compare intra- and postoperative morbidity in patients treated by cervicotomy or cervicosternotomy for intrathoracic goiters and standard thyroidectomy.

Methods In a prospectively gathered cohort undergoing thyroid surgery (2010-2019) intra- and postoperative morbidity of cervicotomy $(N=80)$ and cervicosternotomy $(N=15)$ for intrathoracic goiters was compared to each other and to a 'standard' thyroidectomy $(N=1500)$.

Results An intrathoracic extension prior to surgery was found in 95 (6\%) of all thyroidectomies. Eighty patients (84\%) were operated by cervicotomy and $15(16 \%)$ by cervicosternotomy. The risk of temporary recurrent laryngeal nerve palsy was much higher in the cervicosternotomy group (21\%) compared to cervicotomy (4\%) and standard thyroidectomy (3\%). The risk of temporary hypocalcemia after cervicotomy (28\%) was comparable to a standard thyroidectomy (32\%) but higher after cervicosternotomy (20\%). No cases of permanent hypocalcemia or laryngeal nerve palsy were observed in both groups with substernal extension. The need for surgical reintervention was significantly higher in the cervicotomy group (6\%) compared to cervicosternotomy (0\%) and standard thyroidectomy (3\%).

Conclusion In patients undergoing thyroid surgery for an intrathoracic goiter, cervicosternotomy was associated with more temporary laryngeal nerve palsy, but none of the interventions resulted in higher risks of permanent nerve damage, permanent hypocalcemia, or reintervention for bleeding. Reintervention was even more common after cervicotomy compared to cervicosternotomy.
\end{abstract}

Level of evidence IV

Keywords Thyroid $\cdot$ Intrathoracic goiter $\cdot$ Surgery $\cdot$ Sternotomy $\cdot$ Morbidity $\cdot$ Hypocalcemia $\cdot$ Nerve paralysis

\section{Introduction}

Although there is no uniform definition of an intrathoracic goiter, many agree that a thyroid gland volume over $50 \%$ below the thoracic inlet is an important criterion [1-4]. "Retrosternal" and "substernal" goiters are synonyms. In the

Sam Van Slycke and A.-S. Simons equally contributed to this article.

N. Brusselaers

nele.brusselaers@uantwerpen.be

Extended author information available on the last page of the article absence of a clear definition, the exact prevalence is difficult to determine. In patients undergoing thyroid surgery, the prevalence of intrathoracic goiters is approximately $1-21 \%$ $[1,2,5]$.

In the case of an asymptomatic cervical goiter, conservative treatment may be followed [6]. In case of an asymptomatic, intrathoracic goiter two valid options are available: surgery or observation with monitoring. These options depend on the size of the substernal goiter and the patient characteristics (fit for surgery or not). Possible risks of a conservative policy consist of acute airway obstruction, bleeding, vena cava compression, malignancy and major surgery [7]. Suppressive hormonal therapy can 
reduce goiters in size, but in most cases, this will not be sufficient to alleviate compressive symptoms $[6,8]$.

The only successful surgical treatment for intrathoracic goiter is a total thyroidectomy with "en bloc" removal of the intrathoracic part, without capsular disruption $[1,6]$. For this procedure, two different approaches are available: the cervical one through cervicotomy and the thoracic one through cervicosternotomy. In most cases, a cervical approach is sufficient to extract the mediastinal thyroid part by digital manoeuvres [1-6]. In more extensive cases a thoracic access is needed, in particular for goiters descending into the posterior mediastinum and below the aortic arch [1-3,5] or with a diameter larger than the thoracic inlet $[1,5]$. Less frequent are primary intrathoracic goiters, patients with severe kyphosis, superior vena cava syndrome, distortion of mediastinal structures and goiters with malignancy characteristics such as strong adhesions with neovascular capsule and microcalcifications $[1,4,5]$.

This study aimed to assess intra- and postoperative morbidity in patients treated for intrathoracic goiter by cervicotomy or cervicosternotomy in comparison to a total surgical cohort of 1500 patients.

\section{Methods}

\section{Study design}

All consecutive adult patients undergoing thyroid surgery at the Onze Lieve Vrouw (OLV) hospital in Aalst, Belgium were enrolled in a prospective cohort to evaluate morbidity and outcome in a tertiary referral center. Recruitment of patients was started in January 2010 and is still ongoing. All data have been collected in a prospective manner, and all consecutive patients during the study were invited to participate (none declined consent). The cohort is registered at Research Registry (researchregistry6182) in accordance with the World Medical Association's Declaration of Helsinki 2013.

\section{Setting}

All procedures were performed by a single, extensively trained endocrine surgeon (SVS), with a personal experience of over 5000 cases and an annual caseload of over 250 cases a year. The OLV Hospital in Aalst is the ninth largest general hospital in Belgium, with 844 recognized beds. It is a tertiary referral center for endocrine surgery. In 2018, almost 57,000 surgical interventions were performed and over 1 out of 30 thyroidectomies in Belgium is performed at this hospital.

\section{Ethics}

Prospective data collection in these patients has been approved by the Ethics Committee of the OLV Hospital in Aalst, and all patients provided written informed consent.

\section{Study participants}

The database was locked and ready for analysis on November 11th, 2019. In the overall cohort, all patients receiving surgery for intrathoracic goiter were selected and compared to the first 1500 consecutive patients operated for other thyroid conditions (referred to as 'standard thyroidectomy'). The study cohort is outlined in supplementary Fig. 1. In the presence of a retrosternal goiter (on ultrasound or on clinical examination) a CT-scan was performed. The indication for surgery and choice of surgical technique was discussed at a multidisciplinary meeting, consisting of at least one radiologist, nuclear medicine specialist, endocrinologist, endocrine surgeon and pathologist. In case of a suspicious nodule on US, a fine needle aspiration was always recommended and performed to exclude a possible malignancy, regardless of the size of the thyroid or the possible retrosternal extent. More extended multidisciplinary planning was done for patients undergoing a possible cervicosternotomy, including a pulmonary check-up by an anesthesiologist and pneumologist, with lung function testing and bronchoscopy. The choice of the endotracheal tube size for anaesthesia was based on findings of the bronchoscopy and measurements of tracheal diameter on imaging. Pre-operative respiratory physiotherapy was foreseen to reduce the risk of pulmonary complications.

\section{Surgical characteristics}

As proposed by the IONM study group guidelines, preoperative laryngoscopy was performed before surgery and IONM was used in every single case as part of our routine protocol.

Cervicosternotomy was used for goiters if $50 \%$ of the volume was located below the plane of the thoracic inlet and/or if an additional risk factor was present: wider than the thoracic inlet, diving below the aortic arch or in the posterior mediastinum. A cervicotomy was used for goiters without any of the above findings.

Surgery for an intrathoracic goiter always starts with a Kocher incision, exactly the same as the classic cervical approach. After identifying the recurrent laryngeal nerve, it is monitored and followed further down using the 'toboggan technique' as described by Charles Proye [10]. Intraoperative neuromonitoring during thyroid surgery is used in all cases to improve vigilance [11, 12]. It consists of an 
Fig. 1 Preoperative Computed Tomography: intrathoracic goiter (a) in anterior mediastinum, (b) in posterior mediastinum, (c) extending below the carina (d) causing trachea deviation and narrowing
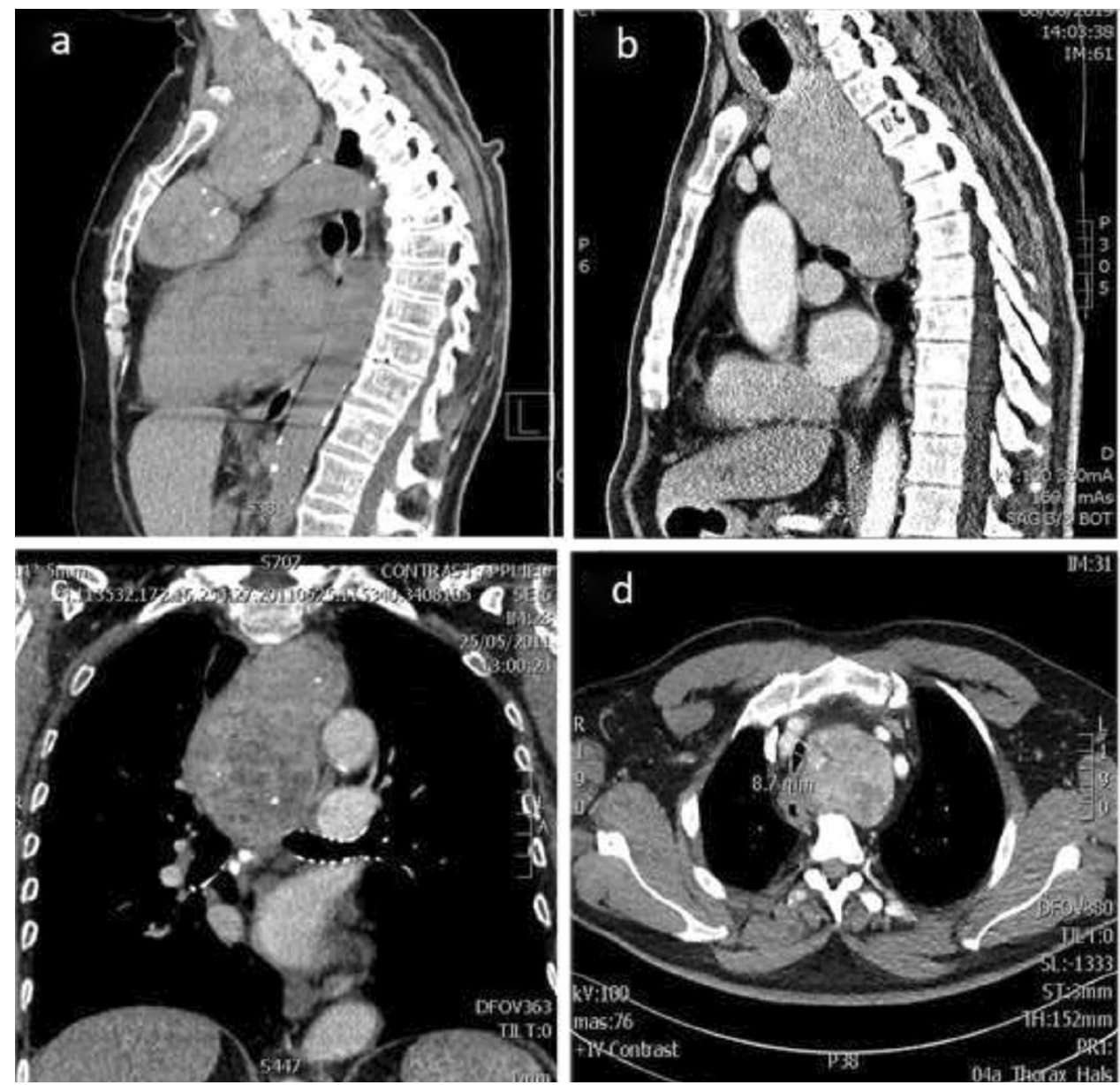

S-shaped probe for continuous vagal stimulation, a handheld bipolar stimulator and acquisition electrodes as previously described [13, 14].

Based on the preoperative multidisciplinary discussion and the perioperative findings, a sternal split is performed when the intrathoracic part cannot be safely delivered.

\section{Definitions}

In our series, the following definition of a substernal goiter was used consistently: more than $50 \%$ of the thyroid is located below the thoracic inlet. Patients selected for surgery for an intrathoracic goiter all received a pre-operative neck ultrasound, and an additional computed tomography (CT) scan or PET-CT scan to determine the optimal surgical technique [3, 9]. In case of a suspicious nodule on US, a fine needle aspiration was always recommended and performed, regardless the size of the thyroid or the possible retrosternal extent to exclude an underlying malignancy.

Permanent hypocalcemia was defined as hypocalcemia lasting at least 6 months after surgery (albumin-corrected calcium level $<2.00 \mathrm{mmol} / \mathrm{l}$ or the need for calcium and/or activated vitamin D substitution to maintain normal calcium levels).

Pre-operative laryngoscopy is performed before anesthetic induction of the patient. Post-operative laryngoscopy is performed within $24 \mathrm{hrs}$ after surgery. In case of a documented RLN palsy, the patient is routinely followed by the ENT and the surgical department until recovery or persistence. Temporary RLN palsy was defined as a recuperation of vocal cord mobility on laryngoscopy within one year after surgery. Permanent palsy was defined as absence of vocal cord mobility on laryngoscopy after a one-year follow-up.

\section{Outcome}

For all patients, data were collected on age (categorized as $<40,40-59$ and $\geq 60$ years), sex (men or women), body mass index (categorized as $<25,25-29$, and $\geq 30 \mathrm{~kg} / \mathrm{m} 2$ ), period of surgery (categorized as 2010-2012, 2013-2015, 2016-2019) and health status as defined by the American Society of Anaesthesiologist association [ASA, categorized as I-II [healthy or mild], and III-IV (severe systemic disease)]. Surgical indications were categorized as multinodular 
goiter, Graves' disease, solitary nodule, toxic adenoma, amiodarone-induced hyperthyreosis and cancer.

Primary outcome variables were: (1) hypocalcemia (transient and permanent), (2) recurrent laryngeal nerve (RLN) palsy (transient and permanent), (3) reintervention for bleeding, (4) Clavien score $\geq 3$ (indicating surgical reintervention). Hypocalcemia was only assessed in individuals receiving a total or completion thyroidectomy and was defined as a parathyroid hormone (PTH) level of $<15 \mathrm{ng} / \mathrm{l} 4 \mathrm{~h}$ after surgery. RLN palsy was only assessed in individuals with normal results at the pre-operative vocal cord assessment (defined as a moving vocal cord on laryngoscopy, performed by an independent ENT specialist).

\section{Statistical analysis}

Descriptive statistics were compared by means of the Chisquare test, with $p$ values $<0.05$ indicating statistically significant results.

All primary outcomes were assessed by means of logistic regression, presented as odds ratios (OR) and 95\% confidence intervals and adjusted for age, sex, BMI, period of surgery, health status, indication for surgery and hemi- or total thyroidectomy. Data on other complications was also collected and described.

Indicators for surgical complexity were weight of the resected specimen (grams), blood loss $(\mathrm{mL})$, duration of surgery (minutes) and length of hospital stay (days). all were presented as median with interquartile ranges (IQR). The indicators were compared between cervicosternotomy and cervicotomy, and standard thyroidectomy by means of the Mann-Whitney $U$ test, with $p$ values $<0.05$ indicating statistically significant differences.

All statistical analyses were conducted in Stata MP14 $\left(\right.$ Stata Corporation ${ }^{\circledR}$ ).

\section{Results}

\section{Patient characteristics}

In this cohort, 1595 patients underwent thyroid surgery. No intrathoracic extension was seen in 1500 . These were all treated through cervicotomy. In 95 patients $(6 \%)$ an intrathoracic goiter was present. Eighty patients had a limited intrathoracic goiter and were operated by cervicotomy. In 15 patients an extensive intrathoracic goiter was present, requiring a resection by cervicosternotomy. Clinical characteristics of the different cohorts are shown in Table 1. Patients undergoing cervicotomy and cervicosternotomy were significantly older than the reference standard thyroidectomy group. A higher proportion of patients were men. BMI and ASA grade were slightly higher among the cervicosternotomy and cervicotomy groups.

Clinical presentation of the 15 patients with extensive intrathoracic goiter is described below. Ten patients (67\%) had compressive symptoms (superior vena cava syndrome, hoarseness or stridor). Four patients had an asymptomatic, but clinically visible goiter. One patient was diagnosed incidentally on a routine chest X-ray. The 15 extensive retrosternal goiters were located in the anterior $(N=4$, Fig. 1a) and posterior mediastinum $(N=11$, Fig. 1b). Twelve goiters reached below the aortic arch (Fig. 1c, Fig. 2). The first rib, the upper edge of the manubrium and the posterior edge of the first thoracic vertebrae were the landmarks to determine the thoracic inlet on CT-scan. Eight goiters had a larger diameter in the axial plane than the diameter of thoracic inlet, 13 goiters crossed the midline. One of the 15 goiters showed malignancy characteristics. There were no primary intrathoracic goiters. All 95 patients with a suspected retrosternal thyroid on US or on clinical examination underwent a CT scan. In the control group, an additional 365 patients underwent a CT scan for other reasons. Sixty-Eight percent of all 1595 patients underwent a scintigraphy. Only 69 patients in the whole cohort underwent a PET/CT.

\section{Primary outcomes}

No cases of permanent hypocalcemia were recorded after total thyroidectomy by cervicosternotomy. However, $20 \%$, $28 \%$ and $32 \%$ of cervicosternotomy, cervicotomy and standard thyroidectomy cases developed a transient hypocalcemia (Table 2a), however not resulting in statistically different risks after adjustment for confounding variables (Table 3).

No cases of permanent RLN palsy were observed for all retrosternal goiters. Three cases of transient nerve palsy were observed in the cervicotomy and cervicosternotomy groups (Table 2a), resulting in an increased risk of RLN paralysis for cervicosternotomy compared to standard thyroidectomy after adjustment for confounding variables $[\mathrm{OR}=4.20$ (1.03-17.07)] (Table 3).

There were no surgical reinterventions for bleeding in the cervicosternotomy group, and only $5(6 \%)$ and $39(3 \%)$ in the cervicotomy and standard thyroidectomy groups (Table 2a). Differences were not statistically significant (Table 3 ).

Three patients of the cervicosternotomy group had pulmonary morbidity, including a post-sternotomy syndrome with persistent pleural effusion, a postoperative pneumonia and a right apical pneumothorax. None of the patients receiving cervicotomy or standard thyroidectomy had pulmonary complications (Fig. 2). 
Table 1 Descriptive characteristics of all individuals operated by cervicosternotomy or cervicotomy for an intrathoracic goiter, compared to standard thyroidectomy

\begin{tabular}{lllll}
$\begin{array}{l}\text { Standard thyroidectomy } \\
\text { (reference, } N=1500)\end{array}$ & \multicolumn{2}{l}{ Cervicotomy $(N=80)$} & & \multicolumn{2}{l}{$\begin{array}{l}\text { Cervicosternotomy }(N=15) \\
N(\%)\end{array}$} & $N(\%)$ & $\begin{array}{l}p \text { value } \\
\text { (Chi-square) }\end{array}$ & & $N(\%)$ & $\begin{array}{l}p \text { value } \\
\text { (Chi-square) }\end{array}$ \\
\cline { 2 - 3 } & & &
\end{tabular}

\begin{tabular}{|c|c|c|c|c|c|}
\hline \multicolumn{6}{|l|}{ Age (years) } \\
\hline$<40$ & $289(19.3)$ & $2(2.5)$ & \multirow[t]{3}{*}{$<0.001$} & $0(0.0)$ & \multirow[t]{3}{*}{$<0.001$} \\
\hline $40-59$ & $714(47.6)$ & $30(37.5)$ & & $0(0.0)$ & \\
\hline$\geq 60$ & $497(33.1)$ & $48(60.0)$ & & $15(100)$ & \\
\hline \multicolumn{6}{|l|}{ Sex } \\
\hline Male & $304(20.3)$ & $30(37.5)$ & \multirow[t]{2}{*}{$<0.001$} & $10(66.7)$ & \multirow[t]{2}{*}{$<0.001$} \\
\hline Female & $1196(79.7)$ & $50(62.5)$ & & $5(33.3)$ & \\
\hline \multicolumn{6}{|l|}{ Body mass index $\left(\mathrm{kg} / \mathrm{m}^{2}\right)$} \\
\hline$<25$ & $690(46.0)$ & $24(30.0)$ & \multirow[t]{3}{*}{0.004} & $4(26.7)$ & \multirow[t]{3}{*}{0.263} \\
\hline $25-29.9$ & $522(34.8)$ & $30(37.5)$ & & $8(53.3)$ & \\
\hline$\geq 30$ & $288(19.2)$ & $26(32.5)$ & & $3(20.0)$ & \\
\hline \multicolumn{6}{|l|}{ ASA-score } \\
\hline I (healthy) or II (mild) & $1333(88.9)$ & $61(74.2)$ & \multirow[t]{2}{*}{0.001} & $7(46.7)$ & \multirow[t]{2}{*}{$<0.001$} \\
\hline III-IV (severe or life threatening) & $167(11.1)$ & $19(23.8)$ & & $8(53.3)$ & \\
\hline \multicolumn{6}{|l|}{ Pre-op vocal cord assessment } \\
\hline Abnormal & $19(1.3)$ & $1(1.3)$ & 0.990 & $1(6.7)$ & 0.068 \\
\hline \multicolumn{6}{|l|}{ Thyroidectomy } \\
\hline Partial & $457(30.5)$ & $12(15.0)$ & \multirow[t]{2}{*}{0.003} & $5(33.3)$ & \multirow[t]{2}{*}{0.810} \\
\hline Total & $1043(69.5)$ & $68(85.0)$ & & $10(66.7)$ & \\
\hline \multicolumn{6}{|l|}{ Indication } \\
\hline Benign & $1,408(93.9)$ & $78(97.5)$ & \multirow[t]{2}{*}{0.181} & $14(93.3)$ & \multirow[t]{2}{*}{0.932} \\
\hline Malign & $92(6.1)$ & $2(2.5)$ & & $1(6.7)$ & \\
\hline \multicolumn{6}{|l|}{ Indication benign } \\
\hline Multinodular goiter & $785(52.3)$ & $67(83.8)$ & \multirow[t]{5}{*}{$<0.001$} & $14(93.3)$ & \multirow[t]{5}{*}{0.052} \\
\hline Graves & $158(10.5)$ & $2(2.5)$ & & $0(0.0)$ & \\
\hline Solitary nodule & $375(25.0)$ & $6(7.5)$ & & $0(0.0)$ & \\
\hline Toxic adenoma & $64(4.3)$ & $2(2.5)$ & & $0(0.0)$ & \\
\hline Amiodarone & $26(1.7)$ & $1(1.3)$ & & $0(0.0)$ & \\
\hline \multicolumn{6}{|l|}{ Year of surgery } \\
\hline 2010-2012 & $515(34.3)$ & $3(3.8)$ & \multirow[t]{3}{*}{$<0.001$} & $1(6.7)$ & \multirow[t]{3}{*}{0.006} \\
\hline 2013-2015 & $466(31.1)$ & $3(3.8)$ & & $3(20.0)$ & \\
\hline 2016-2019 & $519(34.6)$ & $74(92.5)$ & & $11(73.3)$ & \\
\hline
\end{tabular}

p-values $<0.05$ are considered statistically significant

ASA American Society for Anaesthesiology

\section{Surgical complexity indicators}

For hemithyroidectomies in the cervicotomy group, the duration of surgery was slightly longer compared to standard hemithyroidectomy (median $53 \mathrm{~min}$ compared to $40 \mathrm{~min}$ ). For total thyroidectomies, the weight of the resected specimen (median $123 \mathrm{~g}$ versus $64 \mathrm{~g}$ ), the amount of blood loss $(37 \mathrm{~mL}$ versus $18 \mathrm{~mL}$ ) and duration of surgery (73 min versus $65 \mathrm{~min}$ ) were higher compared to the standard thyroidectomy group. In the cervicosternotomy group, the weight of the resected specimen and blood loss were higher, and the duration of surgery and length of stay longer compared to standard thyroidectomy, for both hemi-thyroidectomy and total thyroidectomy (Table $2 b$ ).

\section{Discussion}

This surgical cohort of 1500 consecutive thyroid surgery procedures contains one of the largest series of retrosternal goiters ever reported. All procedures were carried out using a standardized approach and standardized definitions and 
Table 2 (a) Post-operative morbidity and (b) indicators of surgical complexity in all individuals operated by cervicosternotomy or cervicotomy for retrosternal goiters, compared to standard thyroidectomy

\begin{tabular}{|c|c|c|c|c|c|}
\hline \multirow[t]{2}{*}{ Primary results } & \multirow{2}{*}{$\begin{array}{l}\text { Standard thyroidectomy } \\
\text { (reference) } \\
(N=1500) \\
N(\%)\end{array}$} & \multicolumn{2}{|c|}{ Cervicotomy $(N=80)$} & \multicolumn{2}{|c|}{ Cervicosternotomy $(N=15)$} \\
\hline & & $N(\%)$ & $\begin{array}{l}p \text { value (Chi- } \\
\text { square) }\end{array}$ & $N(\%)$ & $\begin{array}{l}p \text { value (Chi- } \\
\text { square) }\end{array}$ \\
\hline \multicolumn{6}{|c|}{ Hypocalcemia (only in total thyroidectomy) } \\
\hline All & $365(35.0)$ & $19(27.9)$ & 0.236 & $2(20.0)$ & 0.322 \\
\hline Transient & $333(31.9)$ & $19(27.9)$ & 0.395 & $2(20.0)$ & 0.386 \\
\hline Permanent & $32(3.1)$ & $0(0.0)$ & 0.129 & $0(0.0)$ & 0.539 \\
\hline \multicolumn{6}{|c|}{ Recurrent laryngeal nerve palsy (only with normal preoperative vocal cords) } \\
\hline All & $65(4.4)$ & $3(3.8)$ & 0.802 & $3(21.4)$ & 0.002 \\
\hline Transient & $41(2.8)$ & $3(3.8)$ & 0.610 & $3(21.4)$ & $<0.001$ \\
\hline Permanent & $24(1.6)$ & $0(0.0)$ & 0.257 & $(0.0)$ & 0.666 \\
\hline $\begin{array}{l}\text { Surgical reintervention for bleed- } \\
\text { ing }\end{array}$ & $39(2.6)$ & $5(6.3)$ & 0.053 & $0(0.0)$ & 0.527 \\
\hline $\begin{array}{l}\text { Clavien score } \geq 3 \text { (requiring surgi- } \\
\text { cal intervention) }\end{array}$ & $39(2.6)$ & $2(2.5)$ & 0.956 & $0(0.0)$ & 0.527 \\
\hline \multicolumn{6}{|l|}{ (b) } \\
\hline \multirow[t]{2}{*}{ Indicators for surgical complexity } & $\begin{array}{l}\text { Standard thyroidectomy } \\
\text { (reference) } \\
(N=1500)\end{array}$ & \multicolumn{2}{|c|}{ Cervicotomy $(N=80)$} & \multicolumn{2}{|c|}{ Cervicosternotomy $(N=15)$} \\
\hline & Median (interquartile range) [max] & $\begin{array}{l}\text { Median (inter- } \\
\text { quartile range) } \\
{[\max ]}\end{array}$ & $\begin{array}{l}p \text { value } \\
\text { (Mann-Whit- } \\
\text { ney } U \text { ) }\end{array}$ & $\begin{array}{l}\text { Median (inter-quar- } \\
\text { tile range) [max] }\end{array}$ & $\begin{array}{l}p \text { value } \\
(\text { Mann- } \\
\text { Whitney } U \text { ) }\end{array}$ \\
\hline \multicolumn{6}{|l|}{ Hemi-thyroidectomy } \\
\hline $\begin{array}{l}\text { Weight of resected specimen } \\
\text { (grams) }\end{array}$ & $\begin{array}{l}26(16-44) \mathrm{g} \\
{[298 \mathrm{~g}]}\end{array}$ & $\begin{array}{l}33(20-70) \mathrm{g} \\
{[152 \mathrm{~g}]}\end{array}$ & 0.225 & $\begin{array}{l}355(280-378) \mathrm{g} \\
{[378 \mathrm{~g}]}\end{array}$ & 0.003 \\
\hline Length of stay (days) & $\begin{array}{l}1(1-1) \text { days } \\
{[15 \text { days }]}\end{array}$ & $\begin{array}{l}1 \text { (1-1) days } \\
{[1 \text { day }]}\end{array}$ & 0.320 & $\begin{array}{l}7 \text { (4-8) days } \\
\text { [8 days }]\end{array}$ & $<0.001$ \\
\hline Blood loss (mL) & $\begin{array}{l}6(2-13) \mathrm{mL} \\
{[498 \mathrm{~mL}]}\end{array}$ & $\begin{array}{l}10(4-32) \mathrm{mL} \\
{[600 \mathrm{~mL}]}\end{array}$ & 0.126 & $\begin{array}{l}374(263-695) \mathrm{mL} \\
{[1000 \mathrm{~mL}]}\end{array}$ & $<0.001$ \\
\hline Duration of surgery (minutes) & $\begin{array}{l}40(35-50) \mathrm{min} \\
{[275 \mathrm{~min}]}\end{array}$ & $\begin{array}{l}53(40-70) \mathrm{min} \\
{[90 \mathrm{~min}]}\end{array}$ & 0.041 & $\begin{array}{l}140(135-140) \mathrm{min} \\
{[300 \mathrm{~min}]}\end{array}$ & $<0.001$ \\
\hline \multicolumn{6}{|l|}{ Total thyroidectomy } \\
\hline $\begin{array}{l}\text { Weight of resected specimen } \\
\quad \text { (grams) }\end{array}$ & $\begin{array}{l}64(36-112) \mathrm{g} \\
{[848 \mathrm{~g}]}\end{array}$ & $\begin{array}{l}123(69-172) \mathrm{g} \\
{[528 \mathrm{~g}]}\end{array}$ & $<0.001$ & $\begin{array}{l}430(400-502) \mathrm{g} \\
{[776 \mathrm{~g}]}\end{array}$ & $<0.001$ \\
\hline Length of stay (days) & $\begin{array}{l}1(1-1) \text { days } \\
{[13 \text { days }]}\end{array}$ & $\begin{array}{l}1(1-1) \text { days } \\
\text { [21 days }]\end{array}$ & 0.763 & $\begin{array}{l}5(1-7) \text { days } \\
{[10 \text { days }]}\end{array}$ & $<0.001$ \\
\hline Blood loss (mL) & $\begin{array}{l}18(9-38) \mathrm{mL} \\
{[1290 \mathrm{~mL}]}\end{array}$ & $\begin{array}{l}37(14-71) \mathrm{mL} \\
{[536 \mathrm{~mL}]}\end{array}$ & $<0.001$ & $\begin{array}{l}350(204-634) \mathrm{mL} \\
{[1100 \mathrm{~mL}]}\end{array}$ & $<0.001$ \\
\hline Duration of surgery (minutes) & $\begin{array}{l}65(55-85) \mathrm{min} \\
{[540 \mathrm{~min}]}\end{array}$ & $\begin{array}{l}73(60-90) \min \\
{[180 \mathrm{~min}]}\end{array}$ & 0.029 & $\begin{array}{l}180(150-200) \mathrm{min} \\
{[240 \mathrm{~min}]}\end{array}$ & $<0.001$ \\
\hline
\end{tabular}

p-values $<0.05$ are considered statistically significant

recorded without missing data. This single centre, prospective surgical cohort showed a prevalence of $6 \%$ of intrathoracic goiter, comparable to other published data $[2,5,15]$.
In $84 \%$ of all intrathoracic goiters, surgery through cervicotomy was feasible to remove all thyroid tissue. Our number of people treated by cervicosternotomy seems quite high. This could be related to consistently 
Table 3 The risk of hypocalcemia and recurrent laryngeal nerve palsy among individuals operated with cervicotomy or cervicosternotomy compared to standard thyroidectomy, by means of (multivariable) logistic regression

\begin{tabular}{|c|c|c|c|c|c|}
\hline & \multirow[t]{2}{*}{$\begin{array}{l}\text { Standard thyroidec- } \\
\text { tomy (reference) }\end{array}$} & \multicolumn{2}{|c|}{$\begin{array}{l}\text { Cervicotomy } \\
(N=80), \\
\text { odds ratio }(95 \% \mathrm{CI})\end{array}$} & \multicolumn{2}{|c|}{$\begin{array}{l}\text { Cervicosternotomy } \\
(N=15), \\
\text { odds ratio }(95 \% \mathrm{CI})\end{array}$} \\
\hline & & Crude & Adjusted $^{\mathrm{a}}$ & Crude & Adjusted $^{\mathrm{a}}$ \\
\hline Hypocalcemia (transient or permanent) ${ }^{b}$ & 1.00 & $\begin{array}{l}0.72 \\
(0.42-1.24)\end{array}$ & $\begin{array}{l}0.81 \\
(0.46-1.45)\end{array}$ & $\begin{array}{l}0.46 \\
(0.10-2.20)\end{array}$ & $\begin{array}{l}0.50 \\
(0.10-2.46)\end{array}$ \\
\hline $\begin{array}{l}\text { Recurrent laryngeal nerve palsy (transient or } \\
\text { permanent) }^{\mathrm{c}}\end{array}$ & 1.00 & $\begin{array}{l}0.86 \\
(0.26-2.80)\end{array}$ & $\begin{array}{l}0.71 \\
(0.21-2.43)\end{array}$ & $\begin{array}{l}5.94 \\
(1.62-21.81)\end{array}$ & $\begin{array}{l}4.20 \\
(1.03-17.07)\end{array}$ \\
\hline Surgical re-intervention for bleeding & 1.00 & $\begin{array}{l}2.50 \\
(0.96-6.52)\end{array}$ & $\begin{array}{l}1.56 \\
(0.54-4.49)\end{array}$ & - & - \\
\hline Clavien score $\geq 3$ & 1.00 & $\begin{array}{l}0.96 \\
(0.23-4.05)\end{array}$ & $\begin{array}{l}0.63 \\
(0.14-2.85)\end{array}$ & - & - \\
\hline
\end{tabular}

CI confidence interval



${ }^{\mathrm{b}}$ Only individuals receiving total thyroidectomy are included

${ }^{c}$ Only individuals without pre-operative abnormal vocal cord assessment

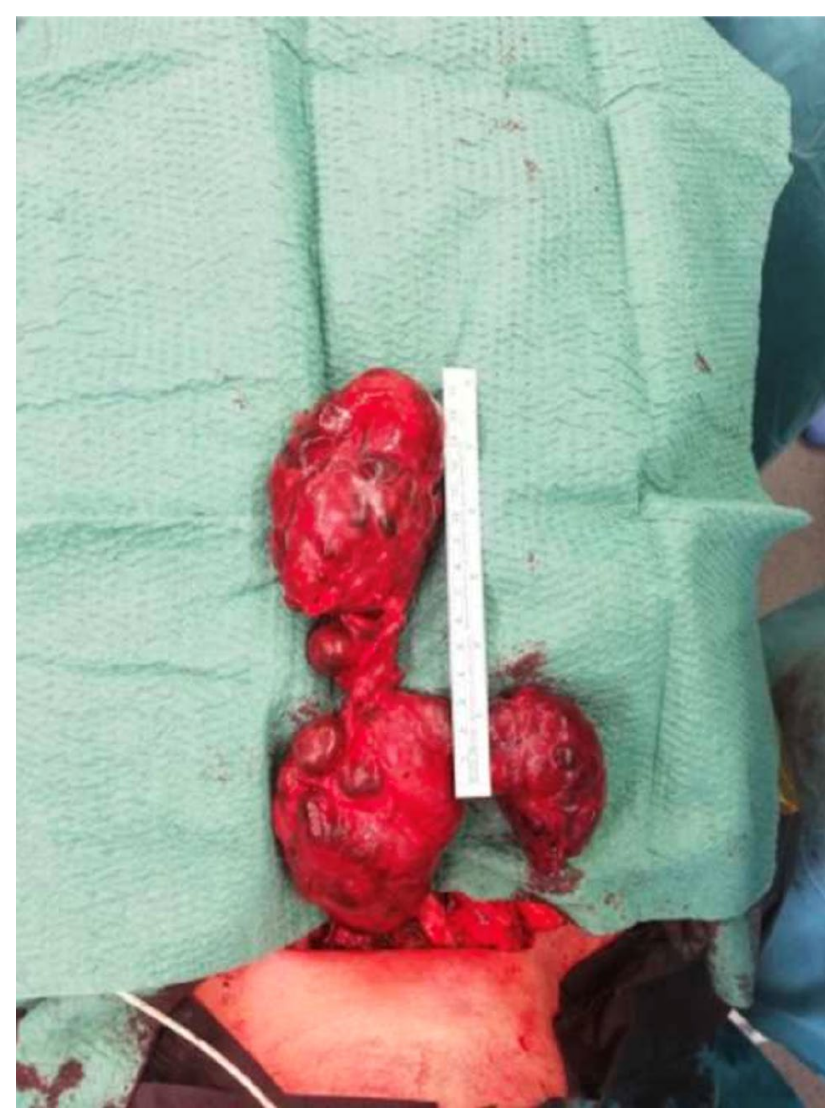

Fig. 2 Specimen of an intrathoracic goiter, weighting $534 \mathrm{~g}$, resected using the thoracic approach in one of the included patients

following the flowchart (Fig. 3) and the fact of being a tertiary referral centre. Immediate morbidity was comparable to a standard thyroidectomy, only transient RLN palsy occurred more after cervicosternotomy. There was no increased risk of permanent hypocalcemia, permanent RLN palsy or reinterventions for bleeding, despite the increased complexity of surgery as shown by increased duration of surgery, blood loss and weight of the specimen. No patients in the sternotomy group developed a keloid scar or excessive scar formation. Remarkably, the incidence of transient hypocalcemia was higher in the standard thyroidectomy group, when comparing to surgery for intrathoracic goiters. This standard thyroidectomy group mainly includes surgery for Graves' disease and thyroid cancer with central neck dissection, both known risk factors for hypoparathyroidism. The absent permanent hypocalcemia in all patients with intrathoracic goiter could be due to the low number of cases, the extensive experience of the surgeon or a surgical bias. In cases with retrosternal goiter, it is of utmost importance to not harm the upper 2 parathyroid glands, because of the high risk of not viewing or damaging the blood supply of the lower parathyroid glands.

The major strengths of this study are the standardized pre-operative preparation, surgical procedure and post-operative follow-up, and the large series of patients operated by a highly experienced endocrine surgeon. In addition, detailed information has been collected on demographics and disease-related characteristics, that could confound the risk of the major complications.

The authors acknowledge there may be residual confounding variables and only a small set of confounders was used because of limited power. However, despite a different baseline situation and an a-priori higher risk of poorer outcome, the differences between the groups were still relatively limited for most outcomes. 




Fig. 3 Flowchart for the decision-making process

According to our experience, surgery for an intrathoracic goiter is especially challenging if the goiter is shaped like an apple and/or crosses the midline of the mediastinum. Previous studies also reported an iceberg-shaped goiter or a pure intrathoracic goiter as an independent risk factor for an extra cervical approach $[15,16]$.

The preoperative decision to use a thoracic approach entails interesting advantages. First of all, the patient can be prepared and informed about the procedure and possible specific risks. Second, the surgeon can be optimally prepared if the decision about the approach is made in advance. Third, the assistance of a thoracic surgeon (if the endocrine surgeon lacks skill to perform a sternotomy and thoracic dissection) and the specific material can be provided. Fourth, the anesthesiologist can make a more accurate preoperative evaluation of the patient and his perioperative needs. Moreover, when a thoracic approach is indicated and a cervical approach is applied instead, the risk of complications may increase. In specific, the performance of digital manipulations to retract the intrathoracic part of the goiter will increase the risk of incomplete removal and morcellation of the thyroid resulting in a "forgotten" goiter [1]. This is mediastinal thyroid tissue remaining after a so-called "total" thyroidectomy. Another risk of morcellation is soiling in the case of a malignant goiter. Performing a thoracic approach can reduce the risk of a traumatic hemorrhage, because the surgeon is not dissecting blindly in the area of the great vessels $[1,2,7,16]$. Additionally, there are arguments for a reduced risk of RLN palsy and hypoparathyroidism in a thoracic approach compared to digitally cervical retraction [4, 7]. More blood loss during surgery and an increased hospital stay have been reported for cervicosternotomy compared to cervical approaches [2]. This was confirmed in the present study. This highlights the increased complexity of the surgical procedure when adding a sternotomy. However, cervicosternotomy does not lead to an excessive risk of major complications including RLN palsy and hypocalcemia, besides an increased risk of pulmonary complications $[4,7,9,15$, 17]. No reintervention for bleeding was noted in the cervicosternotomy group in our series. It is a fact that mediastinal vessel exposure, mediastinal vessel ligation and intraoperative bleeding control from the mediastinum are better with sternotomy compared to the 'blind', manual dissection in case of cervicotomy.

Understanding the benefits and disadvantages and determining the probability of a thoracic approach still remain the 
biggest challenges. Every preoperative planning for thyroid surgery, either cervical or thoracic, requires an ultrasound. A supplementary scintigraphy can be carried out if the thyroidstimulating hormone is low or suppressed. If the ultrasound indicates a risk of a retrosternal goiter or when the border of the lower pole can't be felt on clinical examination, a neck and chest CT should be done to evaluate its size and location in relation to the surrounding structures [1-4].

Because the more invasive nature does not translate into more associated morbidity, recent literature suggests that a thoracic approach should be considered more often in the preoperative phase $[2,18]$. Not every goiter reaching below the aortic arch needs a thoracic approach. It must be emphasized that there is no reason to avoid the use of this type of access, keeping in mind the benefits, or the risk of forgotten goiters in intrathoracic goiter which would need an invasive procedure afterwards anyway $[1,5,18]$.

Based on this information and our own experience, we created a flow chart, which can guide surgeons in the preoperative decision-making process for dealing with multinodular goiters (Fig. 3). The algorithm shows that in the case of an asymptomatic cervical goiter, a conservative approach is recommended. In case of a substernal goiter, a CT-scan should be performed, and surgery discussed with the patient to prevent future complications. In most cases, a full sternotomy is preferred as it provides excellent visualization of the goiter, mediastinum and related structures [4]. In some cases, a less invasive approach can be sufficient: sternal split, lateral thoracotomy and posterolateral thoracotomy are described previously $[1,4,19]$.

In conclusion, this study shows that despite its invasiveness, surgery for goiters with retrosternal extension is safe without an excessive risk of major complications. Reintervention was higher in the cervicotomy group compared to the cervicosternotomy group. An extensive standardized pre-operative preparation, a CT-scan to determine the extent and complexity and multidisciplinary approach are crucial in surgical decision making.

Supplementary Information The online version contains supplementary material available at https://doi.org/10.1007/s13304-021-01027-1.

Acknowledgements we would like to warmly thank the patients who participated in the study, and the whole clinical team involved in the treatment of the patients; with a special thank you to Dr. K. Magamadov.

Funding Open access funding provided by Karolinska Institute.

\section{Declarations}

Conflicts of interest The authors have no conflicts of interest, and no funding was acquired.
Availability of data and material Although the data are anonymised, these can not be shared open access because of the detailed information on all patients. Upon reasonable request (and necessary approval of the ethics committee), the corresponding author can be contacted for potential access to the data.

Ethics approval All procedures performed in studies involving human participants were in accordance with the ethical standards of the institutional and/or national research committee and with the 1964 Helsinki declaration and its later amendments or comparable ethical standards. The study was approved by the Ethics Committee from the OLV Hospital, Aalst Belgium. Informed consent: Informed consent was obtained from all participants in the study.

Informed consent Informed consent was obtained from all participants in the study.

Open Access This article is licensed under a Creative Commons Attribution 4.0 International License, which permits use, sharing, adaptation, distribution and reproduction in any medium or format, as long as you give appropriate credit to the original author(s) and the source, provide a link to the Creative Commons licence, and indicate if changes were made. The images or other third party material in this article are included in the article's Creative Commons licence, unless indicated otherwise in a credit line to the material. If material is not included in the article's Creative Commons licence and your intended use is not permitted by statutory regulation or exceeds the permitted use, you will need to obtain permission directly from the copyright holder. To view a copy of this licence, visit http://creativecommons.org/licenses/by/4.0/.

\section{References}

1. Di Crescenzo V, Vitale M, Valvano L, Napolitano F, Vatrella A, Zeppa P, De Rosa G, Amato B, Laperuta P (2016) Surgical management of cervico-mediastinal goiters: our experience and review of the literature. Int J Surg (London, England) 28(Suppl 1):S47-53

2. Nankee L, Chen H, Schneider DF, Sippel RS, Elfenbein DM (2015) Substernal goiter: when is a sternotomy required? J Surg Res 199(1):121-125

3. Qureishi A, Garas G, Tolley N, Palazzo F, Athanasiou T, Zacharakis $\mathrm{E}$ (2013) Can pre-operative computed tomography predict the need for a thoracic approach for removal of retrosternal goitre? Int J Surg (London, England) 11(3):203-208

4. Rolighed L, Ronning H, Christiansen P (2015) Sternotomy for substernal goiter: retrospective study of 52 operations. Langenbecks Arch Surg 400(3):301-306

5. White ML, Doherty GM, Gauger PG (2008) Evidence-based surgical management of substernal goiter. World J Surg 32(7): 1285-1300

6. Hardy RG, Bliss RD, Lennard TW, Balasubramanian SP, Harrison BJ (2009) Management of retrosternal goitres. Ann R Coll Surg Engl 91(1):8-11

7. Testini M, Gurrado A, Avenia N, Bellantone R, Biondi A, Brazzarola P, Calzolari F, Cavallaro G, De Toma G, Guida P, Lissidini G, Loizzi M, Lombardi CP, Piccinni G, Portincasa P, Rosato L, Sartori N, Zugni C, Basile F (2011) Does mediastinal extension of the goiter increase morbidity of total thyroidectomy? A multicenter study of 19,662 patients. Ann Surg Oncol 18(8):2251-2259

8. Shimaoka K, Sokal JE (1974) Suppressive therapy of nontoxic goiter. Am J Med 57(4):576-583

9. Pieracci FM, Fahey TJ 3rd (2007) Substernal thyroidectomy is associated with increased morbidity and mortality as compared 
with conventional cervical thyroidectomy. J Am Coll Surg 205(1):1-7

10. Scarpa CR, Triponez F. (2014) Retrosternal Thyroid Goiter: Recurrent Laryngeal Nerve Dissection According to the Charles Proye's Toboggan Technique. In: VideoEndocrinology https://doi. org/10.1089/VE.2014.0009

11. Schneider R, Randolph GW, Dionigi G, Wu CW, Barczynski M, Chiang FY, Al-Quaryshi Z, Angelos P, Brauckhoff K, Cernea CR, Chaplin J, Cheetham J, Davies L, Goretzki PE, Hartl D, Kamani D, Kandil E, Kyriazidis N, Liddy W, Orloff L, Scharpf J, Serpell J, Shin JJ, Sinclair CF, Singer MC, Snyder SK, Tolley NS, Van Slycke S, Volpi E, Witterick I, Wong RJ, Woodson G, Zafereo M, Dralle H (2018) International neural monitoring study group guideline 2018 part I: staging bilateral thyroid surgery with monitoring loss of signal. Laryngoscope 128(Suppl 3):S1-S17

12. Wu CW, Dionigi G, Barczynski M, Chiang FY, Dralle H, Schneider R, Al-Quaryshi Z, Angelos P, Brauckhoff K, Brooks JA, Cernea CR, Chaplin J, Chen AY, Davies L, Diercks GR, Duh QY, Fundakowski C, Goretzki PE, Hales NW, Hartl D, Kamani D, Kandil E, Kyriazidis N, Liddy W, Miyauchi A, Orloff L, Rastatter JC, Scharpf J, Serpell J, Shin JJ, Sinclair CF, Stack BC, Jr., Tolley NS, Slycke SV, Snyder SK, Urken ML, Volpi E, Witterick I, Wong RJ, Woodson G, Zafereo M, Randolph GW (2018) International neuromonitoring study group guidelines 2018: part II: optimal recurrent laryngeal nerve management for invasive thyroid cancerincorporation of surgical, laryngeal, and neural electrophysiologic data. Laryngoscope 128(Suppl 3):S18-S27

13. Van Slycke S, Gillardin JP, Brusselaers N, Vermeersch H (2013) Initial experience with $\mathrm{S}$-shaped electrode for continuous vagal nerve stimulation in thyroid surgery. Langenbecks Arch Surg 398(5):717-722
14. Van Slycke S, Van Den Heede K, Magamadov K, Brusselaers N, Vermeersch H (2019) New placement of recording electrodes on the thyroid cartilage in intra-operative neuromonitoring during thyroid surgery. Langenbecks Arch Surg 404(6):703-709

15. Simo R, Nixon IJ, Vander Poorten V, Quer M, Shaha AR, Sanabria A, Alvarez FL, Angelos P, Rinaldo A, Ferlito A (2019) Surgical management of intrathoracic goitres. Eur Arch OtoRhino-Laryngol: Offl J Eur Feder Of Oto-Rhino-Laryngol Soc (Eufos): Affil German Soc Oto-Rhino-Laryngol-Head Neck Surg 276(2):305-314

16. Tikka T, Nixon IJ, Harrison-Phipps K, Simo R (2019) Predictors of the need for an extracervical approach to intrathoracic goitre. BJS open 3(2):174-179

17. Wong WK, Shetty S, Morton RP, McIvor NP, Zheng T (2019) Management of retrosternal goiter: retrospective study of 72 patients at two secondary care centers. Auris Nasus Larynx 46(1):129-134

18. Kilic D, Findikcioglu A, Ekici Y, Alemdaroglu U, Hekimoglu K, Hatipoglu A (2011) When is transthoracic approach indicated in retrosternal goiters? Ann Thorac Cardiovasc Surg: Off J Assoc Thorac Cardiovasc Surg Asia 17(3):250-253

19. Huins CT, Georgalas C, Mehrzad H, Tolley NS (2008) A new classification system for retrosternal goitre based on a systematic review of its complications and management. Int J Surg (London, England) 6(1):71-76

Publisher's Note Springer Nature remains neutral with regard to jurisdictional claims in published maps and institutional affiliations.

\section{Authors and Affiliations}

\section{S. Van Slycke ${ }^{1,2,3} \cdot$ A.-S. Simons ${ }^{1,4} \cdot$ K. Van Den Heede ${ }^{1} \cdot$ P. Van Crombrugge ${ }^{5} \cdot$ K. Tournoy ${ }^{6,7} \cdot$ P. Simons ${ }^{8}$. H. Vermeersch ${ }^{2,9} \cdot$ N. Brusselaers ${ }^{2,10,11}$}

1 Department of General and Endocrine Surgery, Onze-LieveVrouw (OLV) Hospital Aalst, Moorselbaan 164, 9300 Aalst, Belgium

2 Department of Head and Skin, University Hospital Ghent, Corneel Heymanslaan 10, 9000 Ghent, Belgium

3 Department of General Surgery, AZ Damiaan, Gouwelozestraat 100, 8400 Ostend, Belgium

4 Group of Biomedical Sciences, University Hospital Leuven, Herestraat 49, 3000 Leuven, Belgium

5 Department of Endocrinology, Onze-Lieve-Vrouw (OLV) Hospital Aalst, Moorselbaan 164, 9300 Aalst, Belgium

6 Department of Pneumology, Onze-Lieve-Vrouw (OLV) Hospital Aalst, Moorselbaan 164, 9300 Aalst, Belgium

7 Department of Internal Medicine and Paediatrics, University Hospital Ghent, Corneel Heymanslaan 10, 9000 Ghent, Belgium
8 Department of Radiology, Onze-Lieve-Vrouw (OLV) Hospital Aalst, Moorselbaan 164, 9300 Aalst, Belgium

9 Plastic and Reconstructive Surgery, Department of Human Structure and Repair, University Hospital Ghent, Corneel Heymanslaan 10, 9000 Ghent, Belgium

10 Department of Microbiology, Tumour and Cell Biology, Centre for Translational Microbiome Research, Karolinska Institutet, Karolinska Hospital, Tomtebodavagen 16, 17165 Stockholm, Sweden

11 Global Health Institute, Antwerp University, Campus Drie Eiken, Gouverneur Kinsbergencentrum, Doornstraat 331, 2610 Wilrijk, Belgium 